\title{
IMMUNOTOXINS, AN ADVANCE TOOL FOR CANCER TREATMENT: REVIEW AND UPDATE
}

\author{
IQRA MUNIR ${ }^{1 *}$, RANA DAWOOD NASEER ${ }^{2}$, AISHA SULTANA ${ }^{2}$, \\ AMINA NASEER $^{2}$, BUSHRA SHAUKAT ${ }^{1}$ and FATIMA SULTANA ${ }^{3}$ \\ 'Department of Pharmaceutical Sciences, Government College \\ University Faisalabad, Pakistan \\ ${ }^{2}$ Institute of Pharmacy, Physiology and Pharmacology \\ University of Agriculture, Faisalabad, Pakistan \\ ${ }^{3}$ Institue of Home and Food Sciences, Government College \\ University Faisalabad, Pakistan
}

\begin{abstract}
Conventional therapeutic approaches like chemotherapy, surgery, and radiation for cancer and other malignancies have a limited success rate. Several factors such as drug resistance, non-penetrability into solid tumors and unwanted toxicity due to non-specific action contribute to treatment failure. To overcome these issues, immunotoxins were developed having a target-specific action. Immunotoxins are chimeric cytotoxic proteins which are formed by linking a toxin moiety to intact antibody or its fragment. Bacterial and plant-based toxins are used in immunotoxins construction but they have many drawbacks in terms of immunogenicity and non-specific toxicity. Recently, a novel class of immunotoxins of human origin has been introduced. Immunotoxins fight back cancers by targeting the neoplastic cells and cause cells death by inhibiting protein synthesis. They have been categorized into two main classes, chemically conjugated immunotoxins and recombinant immunotoxins. The aim of this work is to present recent advances in immunotoxins development and a comprehensive illustration of Immunotoxins sources along with their generations. Moreover, it also summarizes the information regarding future directions to be explored as well as the limitations in immunotoxins development and its use.
\end{abstract}

Keywords: immunogenicity, malignancy, lymphoma

The idea of drug selectivity and target cell killing inspired the hundreds of researchers around the globe after the discovery of "magic bullet concept". This idea was proposed by Paul Ehlrich in 90 's era, which states that drugs enter straight into their target cells to show their selective effect. Since then, many research methodologies have been planned, one of the most prevalent and current approach was based on attaching the carrier molecule with pharmacologically active substance for target cell delivery. These active molecule-carrier conjugates are mainly used in cancer treatment (1). Despite the antineoplastic effects of chemotherapy and radiotherapy, there are some limitations (drug resistance development, lack of neoplastic cell selectivity, occurrence of severe side effects and secondary complications) which provoked the scientists to discover the alternate treatment options with enhanced specificity and reduced toxicity like immunotherapy.

Among various types of immunotherapy techniques, one is conjugated monoclonal antibody (mAb) approach in which $\mathrm{mAb}$ is linked to a chemotherapeutic agent or cytotoxic drug which serves as a carrier/vehicle for a cancer cell. This $\mathrm{mAb}$ conjugate is able to move in every body part until it searches out and attaches itself with the target antigen cell. After fixing, it administers toxic agent at the desired place. Because of greater stability in blood and target cell affinity, antibodies serve as the most used carriers in such therapies. The toxins used in these conjugates are obtained from both bacterial and plant sources. These conjugated toxins offer many advantages over conventional radionuclides in terms of greater activity and stability towards target antigens. In addition, these complex-

* Corresponding author: e-mail: iqra.ahmad143@gmail.com 
es lack drug resistance and kill cells both in dividing and non-dividing phases (2).

\section{Immunotoxins}

Immunotoxins are chimeric molecules which involve the fusion of toxic protein with antibody mainly monoclonal antibody, termed as tumor selective ligand. These immunotoxins are produced by chemical conjugation of antibody with whole toxin protein which has been modified and its natural binding domains are removed. Mostly used toxins are peptides that inhibit the protein synthesis and categorize into plant-based immunotoxins such as abrin, ricin, pokeweed antiviral proteins; bacterial immunotoxins (diphtheria toxin, anthrax toxin, Pseudomonas exotoxin A); ribosomes inactivating proteins (saporin, gelonin) and derivatives of fungus (alpha-sarcin) (3). Yet another class of humanized immunotoxins has also been discovered for cancer therapy in which neoplastic moiety is an endogenous protein of human origin such as RNase or proapoptotic protein (4).

\section{Mechanism of action}

The plant, bacterial and humanized immunotoxins cause cell death by inhibition of protein synthesis through different mechanisms as described in Figure 1.

\section{Sources of immunotoxins}

In the structure of immunotoxin, the toxin moiety is either derived from bacteria, plant or human source. Among bacterial toxins, Pseudomonas exotoxin A (PE) and Diphtheria toxins (DT) are most commonly used which are produced by the gramnegative bacteria i.e. Pseudomonas aeruginosa and positive aerobic bacteria i.e. Corynebacterium diphtheria respectively. The DT and PE both catalyze the reaction involving the ADP ribosylation of histidine699 of Elongation factor-2, which is altered to a residue of diphthamide post-translationally. Both bacterial toxins differ considerably in the sequence of amino acid. Whereas they also vary in their enzymatic and binding domains as the binding domain of $\mathrm{PE}$ toxin is situated at close to its amino-terminal

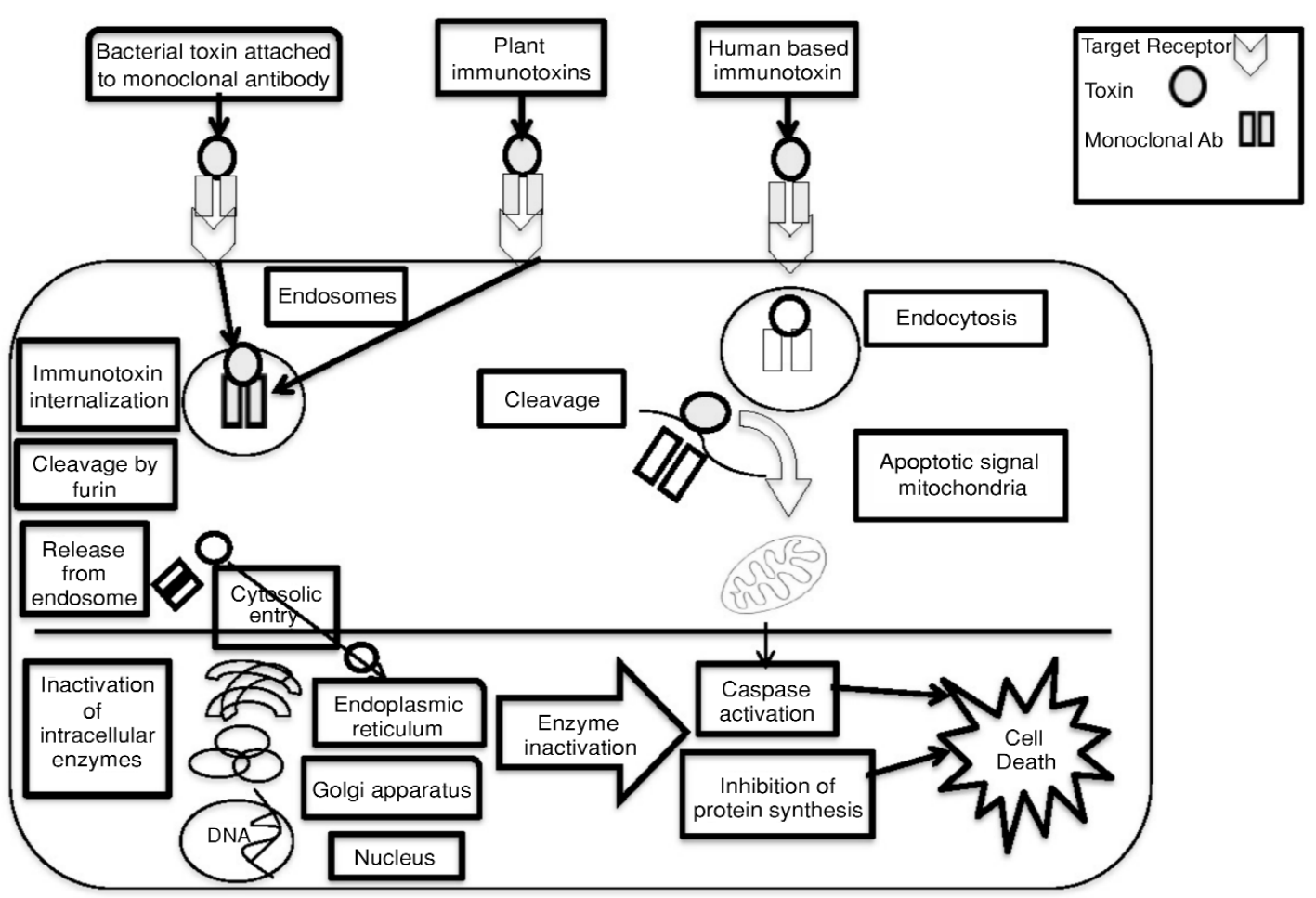

Figure 1. Mechanism of action of immunotoxins

1. Immunotoxin binding to cell surface receptors: toxins first attached to monoclonal antibodies, then the subsequent binding of immunotoxins to cell surface receptor or antigens occur, 2. Immunotoxin internalization: it takes place through clathrin-coated pits and further processing occurs in endosomal compartment, 3. Separation and lysis by furin proteins: cleavage of toxin occur by furin proteins,

4. Release from endosomes into cytosol, 5. Entry into cytoplasm: toxin will enter into cytoplasm where it acts on cytoplasmic organelles like endoplasmic reticulum, Golgi apparatus, 6. Inactivation of intracellular enzymes: it may lead to inhibition of protein synthesis and cell death. Bacterial toxins cause protein inhibition by the ADP ribosylation of EF2 while plant toxins depurinates rRNA. Humanized immunotoxins cause cell death either by inhibiting protein synthesis or by caspases activation. 


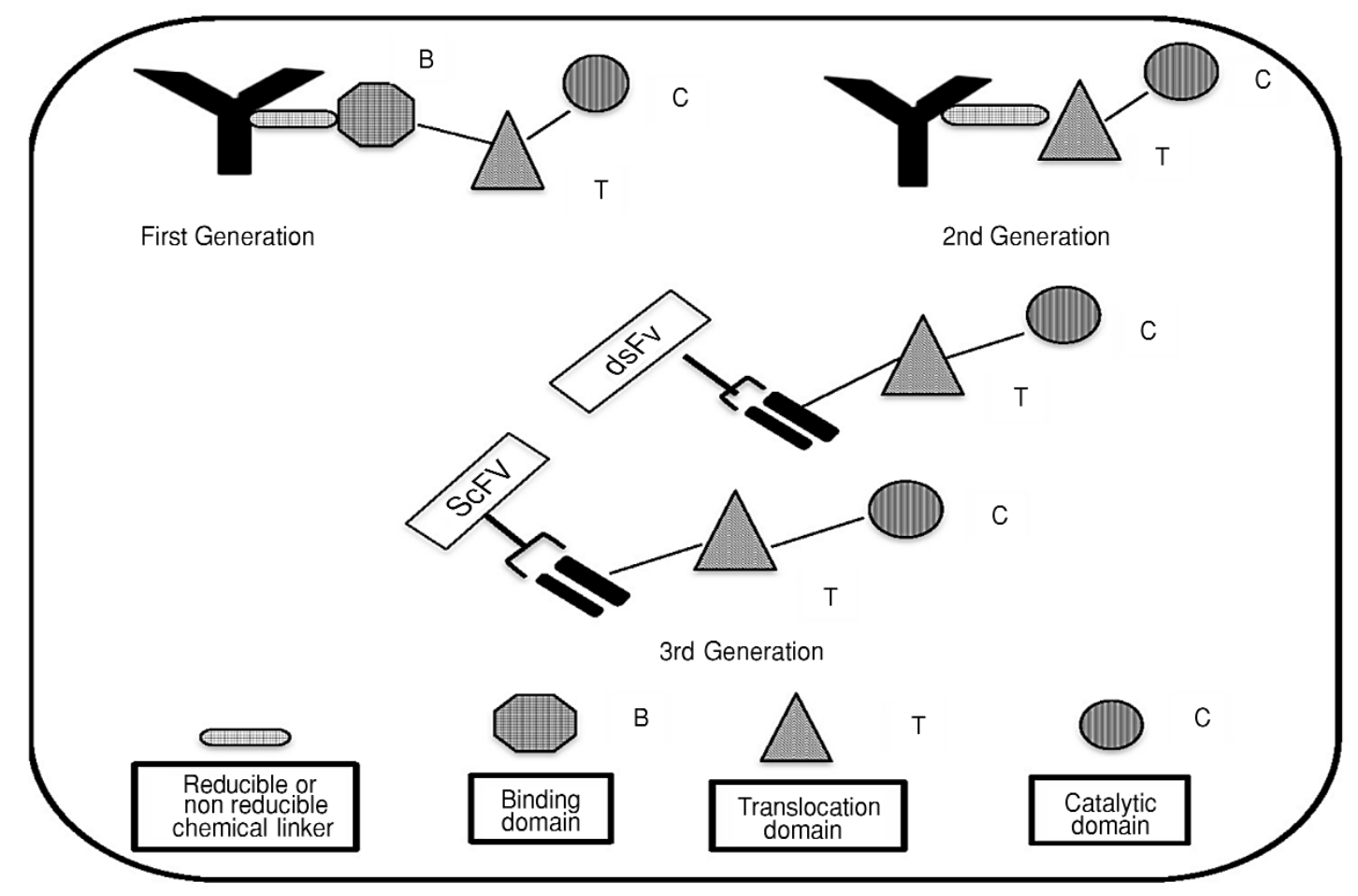

Figure 2. Immunotoxin development from 1 st to $3^{\text {rd }}$ generation

In First generation immunotoxins, intact antibody is attached to an intact toxin at a cell/receptor binding domain through a chemical linker. They are heterogeneous and unspecific. Second generation immunotoxins are target specific and modified proteins lacking the native cell binding domain. They are still heterogeneous but have large size which makes them unable to penetrate solid tumors. Third generation immunotoxins are homogenous proteins and were constructed with recombinant DNA technique and are produced in E. coli. In this type, cell binding domain of toxin is replaced by ligand or Fv portion of the antibody in which its heavy or light chain variables are either genetically linked (scFv) or attached through a disulfide bond (dsFv).

while the binding domain of DT is located near its carboxyl-terminal (5).

\section{Immunotoxin development}

From old to newest generation, immunotoxins develop into three major generations termed as $1^{\text {st }}, 2^{\text {nd }}$ and $3^{\text {rd }}$ generations as shown in Figure 2.

\section{Bacterial toxins and their mechanism of action Diphtheria toxin}

Diphtheria toxin (DT) belongs to a class of AB toxins that has two major parts, $\mathrm{A}$ and $\mathrm{B}$. The fragment $\mathrm{B}$ is required for entry into the cell, receptor binding, and consequent cytoplasmic translocation. While fragment $\mathrm{A}$ is internalized and it causes cell intoxication through its enzymatic activity $(6,7)$. The DT consists of a single protein having 535 amino acids and it has 3 operational domains, first is $\mathrm{N}$ terminal catalytic domain $(\mathrm{C})$ in fragment A having 193 amino acid residues which are also called as DTA. The fragment B (amino acid 194-540) has two domains, one is a translocational ( $\mathrm{T}$ ) domain and the other is receptor binding (R) domain (8) as shown in Figure 3. As above described, toxins bind to the receptor (epidermal growth factor precursor) through its $\mathrm{R}$ domain of fragment $\mathrm{B}$. The polypeptide chain between $\mathrm{C}$ and $\mathrm{T}$ domain is cleaved by furin protease which breaks the disulfide bridge. Then, the endocytosis of complex (toxin-receptor) occurs. The furin proteases cause the cleavage of toxin moiety. Acid-induced conformational change takes place in the $\mathrm{T}$ domain which is injected into endosomal membrane that ultimately creates a channel. The translocation of catalytic domain into cytoplasm can occur through this channel. Finally, the inactivation of elongation factor 2 (eEF2) takes place by ADP-ribosylation which further inhibits translation and leads to cell death.

\section{Pseudomonas Exotoxin A (PE)}

It is a polypeptide consisting of 613 amino acids and is produced by a bacteria Pseudomonas 
aeruginosa. It belongs to a group of $\mathrm{AB}$ toxins and family ADP-ribosylating toxins like DT (9). The PE toxin has further three major functional and structural domains. The $\mathrm{N}$ terminal receptor binding domain $(\mathrm{R})$, translocational domain II (T) that is subdivided into another domain $1 \mathrm{~b}$ and catalytic domain III (C) as shown in Figure 4.

Cell recognition occurs through $\mathrm{N}$-terminal domain Ia having amino acid sequence of 1-252. The toxin translocation through cell membrane takes place by domain II (amino acid residues 253-364). The domain Ib (amino acid 365-404) functional activity is not completely established. The catalytic site is formed by the combination of last four residues of domain Ib along with domain III. After the plasma carboxypeptidases cause the removal of lysine residue at $\mathrm{C}$ terminal, the toxin binds to surface receptor. Then the toxin internalization occurs through clathrin-coated pits. After the conformational change, the toxin cleavage occurs by furin protease in domain II. The products of cleavage get linked through the disulfide bridge. The $\mathrm{C}$ terminal fragment which consists of domain III and half of domain II is directed towards Golgi apparatus after the disulfide bridge reduction. It binds to REDL sequence of KDEL receptor and moves to the endoplasmic reticulum (ER). The inactivation of elongation factor 2 (eEF2) occurs by catalytic domain through ADP-ribosylation which inhibits translation and cause cell death (10).

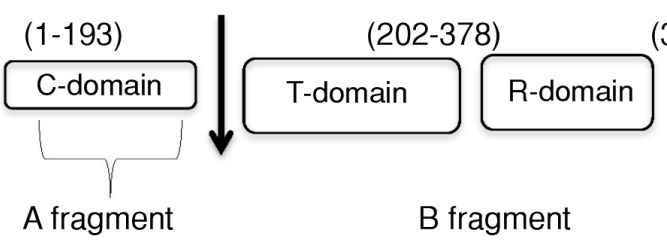

(386-535)

Figure 3. Composition of diphtheria toxin

(1-252)

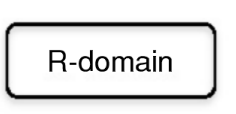

la

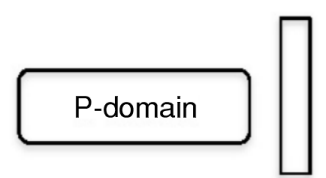

II lb

\section{C-domain}

III

Figure 4. Composition of Pseudomonas Exotoxin A

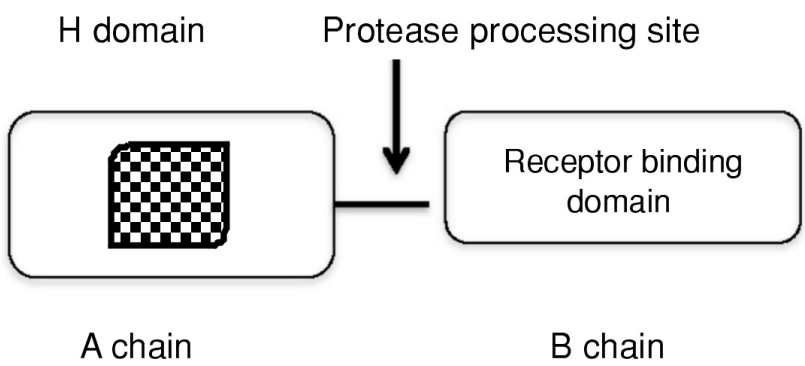

Figure 5. Composition of ricin toxin 


\section{Plant-based immunotoxins}

The toxin moieties are also derived from a plant source which belongs to a group known as "ribosome inactivating proteins" (RIPs). The RIPs include ricin formed by Ricinus communis, pokeweed antiviral proteins (PAP) made by Phytolacca americana and saporin produced by Saponaria officinalis and these toxins are tremendously potent and produce their toxic action in eukaryotic cells through enzymatic inhibition of protein synthesis.

\section{Ribosome inactivating proteins (RIPs)}

RIPs belong to the group of glycosylated and non-glycosylated enzymes that initially originated from higher plants and later on from algae, bacteria, and fungi. The RIPs can lead to cell death by various pathways. Once it reaches into cytoplasm, endoplasmic reticulum or enters into nucleus of the target cell, it causes the triggering of apoptosis, induces oxidative stress, inhibits protein synthesis and activates autophagy $(11,12)$. Furthermore, antibodies also participate in cell death by process of apoptosis, complement-dependent cytotoxicity (CDC) and antibody-dependent cellular cytotoxicity (ADCC).

On the basis of their activation mode and structure, RIPs are distributed into three main groups.

RIPs Type I: also known as hemitoxins. They include saporin, PAP and gelonin which are basic proteins, consisting of single chain catalytic domain and having enzymatic activity.

RIPs Type II: also known as holotoxins. They include ricin, abrin and are heterodimeric proteins composed of two chains A and B. The chain A $(30 \mathrm{kDa})$ is enzymatically active and linked with chain $\mathrm{B}$ having lectin properties $(35 \mathrm{kDa})$ through a disulfide bridge.

RIPs Type III: include barley proteins b-32, maize and JIP60 which are produced in the form of inactive precursors molecules known as pro RIPs. These RIPs do not have lectin and their activation occur after proteolytic processing that is elimination of terminal and deletion of inhibitory internal peptide (13, 14).

\section{Ricin}

The toxin ricin is glycosylated polypeptide produced by Ricinus communis, which consist of two domains, the domain A and a lectin domain B (Fig. 5). The A chain (RTA) involves the enzyme $\mathrm{N}$-glycosidase which causes blockage of ribosomes. Whereas binding of toxin occurs through chain B
(RTB). Upon binding with the target site, the linking peptide of domains A and B gets removed and ultimately disulfide linkage is formed between both domains. The cell surface receptor binding of toxins occur by the lectin B chain. The toxin internalization occurs either through a clathrin-dependent pathway or independent endocytosis. This internalized toxin moves backward from Golgi network to endoplasmic reticulum where the detachment of disulfide chains take place and retranslocation of resulting RTA into cytoplasm occurs. Ricin inhibits translation by disruption of ribosomes which ultimately leads to cell death $(15-24)$.

\section{Resistance to toxin}

There are three different types of toxin resistance; organismal, cellular and immunological. The organismal resistance may occur because in case of whole animal or person, the delivery of toxin to each and every cell can be very challenging; therefore, it may require the repetitive dosing or dose of toxin should be given with such agent which enhances toxin access to neoplastic cells $(25,26)$. Cellular resistance may occur because of ineffective cytosolic delivery, inability to ADPr EF2 (27) or reduced activation of apoptosis (28). The immunological resistance occurs when neutralizing antibodies against the immunotoxin are made by person's own immune system (29). While designing immunotoxins, such improvements can be made in order to produce targeted anti-neoplastic results and minimize each type of resistance. Moreover, such treatment alternatives can be designed which involve the coadministration of immunotoxins along with "helper agents" which could overcome the specific type of resistance.

\section{Immunotoxin-drug combinations/ Immunotoxin enhancers}

From beginnings, combinations were required in order to enhance the activity of immunotoxins. Examples include the addition of monensin or ammonium chloride in cultured cells to increase the sensitivity of plant-based immunotoxins ricin A. Similarly, calcium channel blockers were used to make PE-based immunotoxins more active. The PEbased immunotoxins activity can also be increased by co-transfer with endosome-disrupting adenovirus. Although all these techniques were not useful in vivo because of safety issues and it would be very challenging to attain the required drug concentration. Still, the outcomes increased the efficacy of these combinations to enhance the toxin delivery into cytosol. Moreover, results also emphasized a 
possible concern regarding toxin inefficient trading/transfer into target cell. Retinoic acid causes a destruction of the Golgi network as well as increased about 10000-fold the activity of ricin A chain immunotoxin. The reason of increased cell death was greater toxin delivery into cytosol (30).

The other strategy for designing immunotoxin enhancer was to reduce the effect of pro-survival factors which prevent the cellular exposure to cytotoxic moiety and ultimately cells fail to die (31-33). Another approach has been investigated that directly delivers the targeting moiety to "death" receptors and minimizes the chances of resistance (34). There are certain agents which are used to increase the access of immunotoxin to neoplastic cell like taxol. The previous study proposes that taxol therapy decreases the local concentrations of shed antigen which leads to enhanced access of immunotoxin to tumor cell (26). Except taxol, Bcl-2 proteins are also used to increase immunotoxin activity by neutralizing the survival factors. This strategy is of prime value in many tumor systems especially involving the Bcl2/Bcl-xl inhibitor (ABT-737), which augment the anti-tumor activity of immunotoxin (28). Similarly, the activity of ricin A, a chain-based immunotoxin can be enhanced by the use of Combotox which consist of a combination of two immunotoxins in a 1: 1 ratio. The combination of an anti-CD22 immunotoxin with an anti-CD19 has been developed to overcome the resistance and improve therapeutic outcomes rather than singleagent therapy $(35,36)$. The Combotox and cytarabine combination for B-cell ALL patients have shown promising outcomes in Phase 1 studies (ClinicalTrials.gov Identifier: NCT01408160).

\section{Obstacles in immunotoxin development}

Immunotoxin development process is facing certain challenges. The problems include immunogenicity, resistance, limited half-life, unwanted toxicity and complexity in production.

\section{Immunogenicity}

The origin of monoclonal antibody is either mouse or murine that confers a problem in a way that these antibodies are recognized as foreign antigens by patient's immune system and human immune system remove the antibody quickly from blood. In this way, the efficacy of immunotoxins gets reduced significantly. To overcome this problem, "humanized" monoclonal antibodies are synthesized in which the foreign part of antibody (mouse origin), which is called the constant region, is exchanged with the human constant region. The technique similar to this method is called PEGylation, which is mostly beneficial for chemotherapeutic agents like L-asparaginase and interferons. This method enhances their half-lives and impedes immunogenicity (37).

\section{Unwanted toxicity}

Several toxicities are linked to immunotoxins which restrict the dose and reduce the efficacy. Vascular leak syndrome (VLS) is one of the most common types. Immunotoxins are administered through IV and they come across epithelial cells adjacent to blood vessels. It may lead to VLS which may be fatal enough to cause death. Other toxic effects include hepatotoxicity that may lead to cessation of clinical trials (38). The size of antibody also disturbs potency of immunotoxins. However, cancerous tumors have atypical angiogenesis which enhances leakage and lead to aggregation of molecules having high molecular weight in a tumor portion (39). The penetration into solid tumors is sizerestricted; therefore, immunotoxins efficacy may be enhanced through reduction in its molecular weight.

As immunotoxins are chimeric proteins, their size limitation is about $45 \mathrm{kDa}$. This evidence paved the path for future development of immunotoxins for non-solid tumors in which penetration is not a concern (40).

\section{Production limitations}

During the early development, chemical conjugates were used in clinical trials, as recombinant immunotoxins have to confront obstacles of low production and contamination with endotoxin. The use of recombinant proteins for clinical purpose allowed production of recombinant immunotoxins on a large scale which are cost effective and superior in purity. In future, commercial advancement in immunotoxin development will upgrade yield by reducing costs (41).

\section{Future prospects for advanced development}

In future, the development of recombinant immunotoxins will produce better effects along with reduced toxicity and increased half-lives. Immuntoxins can be employed for microscopic disease treatment after cytoreduction with chemotherapy, radiotherapy or surgery. By selecting the antigens and disease targets carefully, the success and scope of immunotoxins therapy in future can be anticipated for various disorders (41).

Future development may comprise of immunotoxins combinations with other anticancer therapeutic agents to control issues of toxicity, reduced half 
-lives, immunogenicity and difficulty in penetration to solid tumors. These advances in immunotoxins development will finally lead the formation of near to perfection immunotoxins, having high potency and specificity along with little or no disadvantages.

\section{Applications of ITs}

The emerging technique in cancer treatment is targeted drug therapy which can ultimately replace the conventional therapies in the upcoming years. In order to ensure effective cancer therapy, target specific killing of cytotoxic cell is required. Immunotoxins are highly effective moieties for cancer treatment because of having specific binding domains (42).

\section{IT's against hematological malignancies}

Immunotoxins have been employed in multiple hematological disorders ranging from leukemia to several myelomas. Table 1 enlists various studies performed on hematological disorders.

\section{DAB389IL2 or (Ontak $\left.{ }^{\mathrm{TM}}\right)$}

It is the first FDA approved immunotoxin employed for clinical cases such as recurrent cutaneous T-cell lymphoma. Ontak is a chimeric protein molecule consisting of human interleukin-2 (IL-2) and truncated form of DT (DAB389). It specifically binds to high-affinity targets such as IL-2R that is overexpressed in multiple tumors like adult $\mathrm{T}$ cell leukemia (ATL); B \& T cell leukemia's and lymphomas; CTCL and Hodgkin's disease. Ontak has been assessed in the treatment of multiple cancers in combination with other therapeutic agents regardless of their drawbacks and adverse effects (51).

\section{IT's against solid tumors}

The use of immunotoxins against solid tumors encounters certain limitations. The two major problems in immunotoxin development are poor penetration into solid tumors and deactivation of patient's

Table 1. List of immunotoxins effective against various blood-borne cancers.

\begin{tabular}{|c|c|c|c|c|}
\hline Immunotoxin & Target antigen & Toxin moiety & Malignancy & References \\
\hline BL22 & $\mathrm{CD} 22$ & PE38 & Cladribine-resistant HCL & 43 \\
\hline BL22 and RFB4- & $\mathrm{CD} 22$ & PE38 & HCL, CLL, and ALL & 35,36 \\
\hline $\begin{array}{c}\text { Combotox (RFB4-dgA + } \\
\text { HD37-dgA) }\end{array}$ & $\begin{array}{l}\text { CD19, } \\
\text { CD22 }\end{array}$ & Deglycosylated RTA & NHL and ALL & 35 \\
\hline DAB389IL2 & IL-2R & DT & $\begin{array}{c}\text { CTCL, NHL, CLL, NSCLC, } \\
\text { melanoma, ovarian, } \\
\text { and breast cancers }\end{array}$ & $44-46$ \\
\hline DT388 GMCSF & GMCSFR & DT & AML & 47 \\
\hline HA22 & $\mathrm{CD} 22$ & PE38 & HCL, ALL, NHL, and CLL & \\
\hline HD37-dgA & CD19 & Deglycosylated RTA & NHL & 48 \\
\hline HuM195/rGel & CD33 & Gelonin & $\mathrm{AML}$ and $\mathrm{CML}$ & 49,50 \\
\hline
\end{tabular}

$\mathrm{NHL}=$ Non hodgkin lymphoma, $\mathrm{ALL}=$ Acute lymphoblastic leukemia, $\mathrm{HD}=$ Hodgkin disease, $\mathrm{HCL}=\mathrm{Hairy}$ cell leukemia, $\mathrm{CLL}=$ Chronic lymphocytic leukemia, $\mathrm{AML}=$ Acute myeloid leukemia, $\mathrm{CTCL}=$ Cutaneous T-cell lymphomas, SCLC = Small cell lung cancer, GCHD = Graft-versus-host disease, DT = Diphtheria toxin, GMCSFR = Granulocyte-macrophage colony-stimulating factor, Mab = Monoclonal antibody, $\mathrm{scFv}=$ single-chain variable fragment; $\mathrm{dsFv}=$ disulfide-stabilized, $\mathrm{Fv}=$ antibody fragment

Table 2. Reported effect of immunotoxins in clinical trials against different malignancies.

\begin{tabular}{|c|c|c|c|c|}
\hline Immunotoxin & Target antigen & Toxin moiety & Malignancy & References \\
\hline Erb38 & erbB2/HER2 & PE38 & Breast carcinoma & Adenocarcinoma \\
\hline LMB-1 & Lewis Y & PE38 & Adenocarcinoma & 31 \\
\hline LMB-7 & Lewis Y & PE38 & Adenocarcinoma & 10 \\
\hline LMB-9 & Lewis Y & PE38 & Ovarian carcinoma & 53 \\
\hline OvB3-PE & Ovarian cancer & PE & Melanoma, breast, and colon & Mesothelioma, ovarian, and \\
pancreatic cancers & 54 \\
\hline $\begin{array}{c}\text { SS1P (SS1(dsFv)- } \\
\text { PE38) }\end{array}$ & Mesothelin & PE38 & Bladder cancer & 55 \\
\hline TP40 & EGFR & Modified PE40 & &
\end{tabular}


immunity. In order to overcome these problems while designing immunotoxins, novel techniques would be beneficial to improve their efficacy. The immunotoxin therapy against brain tumors provides favorable outcomes. The reason is emergence of novel drug delivery systems which will enhance the penetration of Immunotoxins (52). Table 2 enlists the clinical studies performed against solid tumors.

\section{Immunotoxins against autoimmune disorders}

Targeting surface markers on specific cells are promising in the treatment of autoimmune diseases. Most of the efforts were done in preclinical level and need to be completed (44). Application of anti-CD64ricin immunotoxin clearing of activated synovial macrophages in rheumatoid arthritis was effective in vitro (56). Stepanov and co-workers evaluated in vitro a panel of immunotoxins using the B-cell target moiety c-myc epitope (57). Similar to hematological tumors, Ontak $^{\mathrm{TM}}$ showed promising results in clinical trials of psoriasis and rheumatoid arthritis treatment (58).

\section{Clinical trials}

In the early $1970 \mathrm{~s}$, for the first time, it was found that immunotoxins are potential cancer cell killers. Initially, in primary clinical studies, topical forms of refractory metastatic cancers were treated with a direct injection of toxins with no modification (59). Clinical trials were also performed in order to evaluate the capability of immunotoxins against

Table 3. List of recently investigated immunotoxins under clinical testing.

\begin{tabular}{|c|c|c|c|c|c|c|}
\hline Immunotoxin & Target Antigen & Regimen & Malignancy & $\begin{array}{c}\text { Clinical } \\
\text { trail phase }\end{array}$ & Trail identifier & References \\
\hline $\begin{array}{l}\text { A-dmDT390- } \\
\text { bisfv (UCHT1) }\end{array}$ & CD33/DT & IV single agent & $\begin{array}{l}\text { Cutaneous T-cell } \\
\text { Lymphoma }\end{array}$ & $\mathrm{I} / \mathrm{II}$ & NCT00611208 & 2008 \\
\hline $\begin{array}{l}\text { Denileukin } \\
\text { Diftitox }\end{array}$ & IL-2R/DT & IV single agent & $\begin{array}{l}\text { Cutaneous T-cell } \\
\text { Lymphoma }\end{array}$ & NA & NA open trials & \\
\hline DT2219ARL & DT19/CD22/DT & IV single agent & $\begin{array}{l}\text { B-cell lineage } \\
\text { leukemia } \\
\text { or lymphoma }\end{array}$ & I & NCT00889408 & 2009 \\
\hline $\begin{array}{l}\text { HuM195- } \\
\text { gelonin }\end{array}$ & CD33/gelonin & IV single agent & $\begin{array}{l}\text { AML, CML, } \\
\text { and MDS }\end{array}$ & I & NCT00038051 & 2002 \\
\hline LMB-2 & $\mathrm{CD} 25 / \mathrm{PE}$ & $\begin{array}{c}\text { IV single agent IV } \\
\text { with fludarabine/ } \\
\text { cyclophosphamide }\end{array}$ & $\begin{array}{c}\text { Hairy cell leukemia } \\
\text { Adult T-cell } \\
\text { leukemia }\end{array}$ & $\begin{array}{l}\text { II } \\
\text { II }\end{array}$ & $\begin{array}{l}\text { NCT00321555 } \\
\text { NCT00924170 }\end{array}$ & $\begin{array}{l}2006 \\
2009\end{array}$ \\
\hline MOC31PE & EpCAM/PE & IV single agent & Epithelial carcinomas & $\mathrm{I}$ & NCT01061645 & 2010 \\
\hline $\begin{array}{c}\text { Moxetumomab } \\
\text { Pasudotox }\end{array}$ & $\mathrm{CD} 22 / \mathrm{PE}$ & $\begin{array}{l}\text { IV single agent } \\
\text { IV single agent } \\
\text { IV single agent }\end{array}$ & $\begin{array}{l}\text { Hairy cell leukemia } \\
\text { Adult ALL Childhood } \\
\text { ALL or non-Hodgkin's }\end{array}$ & $\begin{array}{l}\text { III } \\
\text { I/III } \\
\text { I }\end{array}$ & $\begin{array}{l}\text { NCT01829711 } \\
\text { NCT01891981 } \\
\text { NCT00659425 }\end{array}$ & $\begin{array}{l}2015 \\
2013 \\
2015\end{array}$ \\
\hline $\begin{array}{c}\text { Oportuzumab } \\
\text { Monatox }\end{array}$ & EpCAM/PE & & Bladder cancer & In situ & Not listed & \\
\hline SS1P & MSLN/PE & $\begin{array}{c}\text { IV with } \\
\text { pentostatin/ } \\
\text { cyclophosphamide }\end{array}$ & Mesothelioma & II & $\begin{array}{c}\text { Completed } \\
\text { trials }\end{array}$ & \\
\hline
\end{tabular}

Table 4. List of immunotoxins under pre-clinical trials.

\begin{tabular}{|c|c|c|c|c|}
\hline Immunotoxin & Target & Malignancy & Improvement & Year \\
\hline $\begin{array}{c}\text { D2c7-(scdsfv)- } \\
\text { PE38KDEl }\end{array}$ & EGFR and PE & Glioblastoma multiforme & EGFVIII \\
\hline hSGZ & fn14 & Lung, melanoma, and breast & New target & 2013 \\
\hline RG7787 & MSLN & $\begin{array}{c}\text { Mesothelioma, pancreatic, } \\
\text { decreased immunogenicity } \\
\text { cholangiocarcinoma }\end{array}$ & $\begin{array}{c}\text { Reduced toxicity } \\
\text { and } \\
\text { immunogenicity }\end{array}$ \\
\hline VB8-845 & EpCAM & Epithelial carcinoma & Less immunogenic & 2014 \\
\hline
\end{tabular}


blood-borne cancers. Literature review suggests that the use of immunotoxins is beneficial in several malignancies including leukemia, Hodgkin's lymphoma and multiple myeloma (60). Regarding periods of development, various generations of immunotoxins which were clinically evaluated can be distinguished easily. It has been found that the first generation of immunotoxins (e.g. OVB3-PE and 260F9-rRTA) often cause severe side effects that, in many cases, are not followed in the late stages of clinical treatment. The LMB-2 was evaluated in phase-I study that got completed in 2011. In this study, LMB-2 was tested in patients suffering from blood cancer. According to the study, the overall response rate of patients was $24 \%$. Among 35 patients, only 1 patient showed complete response and partial response was observed in 7 patients (61). In 2001, initial approval of Denileukin diftitox (DD) for treatment of cutaneous T-cell lymphoma (CTCL) was granted by the FDA. The DD contains a traditional DT backbone; however, the targeting domain of DD does not contain an antibody. Instead, a recombinant human IL-2 is fused to the first 388 amino acids of DT at C-terminus of the toxin (62). The ligand targets cells that express IL-2R which persistently expresses in a number of hematologic malignancies such as CTCL which makes it a good therapeutic target. Testing of DD in a single-arm phase-III trial in patients with recurrent IL-2-positive CTCL demonstrated a response rate of $30 \%$ with a median response duration of 6.9 months (63). A later randomized, phaseIII, placebo-controlled trial of DD in patients with CTCL confirmed improved overall response rate and progression-free survival with an acceptable safety profile in patients with early- and late-stage CTCL (35). In practice, the DD is not used frequently because of poor tolerability and some side effects such as flu-like symptoms and VLS. Recently investigated immunotoxins are enlisted in Table 3 . Whereas, Table 4 represents some promising immunotoxins under preclinical studies.

\section{SUMMARY}

Various therapies are being utilized in the treatment of cancer. Among them, three approaches are widely used including chemotherapeutic agents, surgical procedure, and radiation therapy. Although, these procedures have some limitations and adverse effects that sometimes overweigh the benefits. Recently, another technique is introduced in which monoclonal antibody is attached with toxic protein via chemical conjugation that is highly selective in action. This therapy is more advantageous in term of targeted action and activity. The toxic moieties are peptides isolated from plant, bacteria and human origins such as ricin protein, diphtheria toxin, and pro-apoptotic protein respectively. Yet, three type of resistance is being observed against immunotoxin i.e. immunological, host-specific (organismal) and cellular. Researches are being carried out to formulate a combination of the drug with immunotoxins. This may lead in an enhanced and dual action of the targeted drug delivery system i.e. immunotoxin. Moreover, chemical like ammonium chloride joined with plant-based ricin may alter the resistance against the immunotoxin. In addition, other strategies like increased and direct exposure of the immunotoxins to the death receptors and decreased action of pro-survival factors are also under investigation. Yet, these procedures have not been proved in in vivo studies. Although, there are several drawbacks associated with the use of these targeted toxic moieties such as immunogenicity: animal originated monoclonal antibodies usually gets eliminated by the immune system when recognized as foreign particles; undesirable toxicity: bacterial toxins may harm the normal cells of the body and may confer some lethal effects i.e. vascular leak syndrome; production limitations, it is not possible for each toxin to be conjugated with monoclonal antibody with optimal purity. Treatment with immunotoxins is promising against cancers including solid tumors, hematological malignancies, and autoimmune disorders. OVB3-PE, 260F9-rRTA, LMB-2 and DD are the immunotoxins being clinically tested in different trails. Among these, DD has shown improved overall response rate and progression-free survival with an acceptable safety profile. Despite the favorable profile, the DD is not used more often as it has lesser tolerability and side effects. Further clinical trials are needed to be performed on immunotoxins such as D2c7-(scdsfv)-PE38KDEl, hSGZ, RG7787, VB8-845 to use them practically with lesser side effects, optimal stability, and improved efficacy.

\section{REFERENCES}

1. Allen T.M.: Nat. Rev. Cancer 2, 750 (2002).

2. Polito L., Djemil A., Bortolotti M.: Biomedicines 4, 1 (2016).

3. Hertler A.A., Frankel A.E.: J. Clin. Oncol. 7, 1932 (1989).

4. Mathew M., Verma R.S.: Cancer. Sci. 100, 1359 (2009).

5. Shapira A., Benhar I.: Toxins. 2, 2519 (2010).

6. Menestrina G., Schiavo G., Montecucco C.: Mol. Aspect. Med. 15, 79 (1994). 
7. Falnes P.O., Sandvig K.: Curr. Opin. Cell. Biol. 12, 407 (2000).

8. Alewine C., Hassan R., Pastan I.: Oncol. 20, 176 (2015).

9. Akbari B., Farajnia S., Khosroshahi S.A., Safari F., Yousefi M. et al.: Int. Rev. Immunol. 36, 1 (2017).

10. Michalska M., Wolf P.: Front. Microbiol. 6, 1 (2015).

11. Polito L., Bortolotti M., Farini V., Battelli M.G., Barbieri L., Bolognesi A.: Int. J. Biochem. Cell. Biol. 41, 1055 (2009).

12. Polito L., Bortolotti M., Pedrazzi M., Mercatelli D., Battelli M.G., Bolognesi A.: Phytomedicine 23, 32 (2016).

13. Nielsen K., Boston R.S.: Annu. Rev. Plant. Physiol. Plant. Mol. Biol. 52, 785 (2001).

14. Stirpe F.: Toxicon 44, 371 (2004).

15. Stirpe F., Battelli M.G.: Cell. Mol. Life Sci. 63, 1850 (2006).

16. Bolognesi A., Bortolotti M., Maiello S., Battelli M.G., Polito L.: Molecules 21, 1 (2016).

17. Spooner R.A., Smith D.C., Easton A.J., Roberts L.M., Lord J.M.: Virol. J. 3, 26 (2006).

18. Allahyari H., Heidari S., Ghamgosha M., Saffarian P., Amani J.: Tumor. Biol. 39, 1 (2017).

19. Deeks E.D., Cook J.P., Day P.J., Smith D.C., Roberts L.M., Lord J.M.: Biochem. 41, 3405 (2002).

20. Wesche J.: Int. J. Med. Microbiol. 291, 517 (2002).

21. Lord J.M., Deeks E., Marsden C.J., Moore K., Pateman C. et al.: Biochem. Soc. Trans. 31, 1260 (2003).

22. Roberts L.M., Lord J.M.: Mini. Rev. Med. Chem. 4, 505 (2004).

23. Spooner R.A., Watson P.D., Marsden C.J., Smith D.C., Moore K.A. et al.: Biochem. J. 383, 285 (2004).

24. Vago R., Marsden C.J., Lord J.M., Ippoliti R., Flavell D.J. et al.: Federation. Eur. Biochem. Societies. J. 272, 4983 (2005).

25. Zhang Y., Hansen J.K., Xiang L., Kawa S., Onda M. et al.: Cancer. Res. 70, 1082 (2010).

26. Zhang Y., Xiang L., Hassan R. Pastan I.: Proc. Natl. Acad. Sci.104, 17099 (2007).

27. Wei H., Xiang L., Wayne A.S., Chertov O., Fitzgerald D.J. et al.: Proc. Natl. Acad. Sci. 109, 6898 (2012).

28. Mattoo A.R., Fitzgerald D.J.: Int. J. Cancer 132, 978 (2013).

29. Posey J.A., Khazaeli M.B., Bookman M.A., Nowrouzi A., Grizzle W.E. et al.: Clin. Cancer. Res. 8, 3092 (2002).
30. Fuchs H., Weng A., Gilabert-Oriol R.: Toxins 8, 2 (2016).

31. Fitzgerald D.J., Moskatel E., Ben-Josef G., Traini R., Tendler T. et al.: Leuk. Lymphoma 52, 79 (2011).

32. Traini R., Ben-Josef G., Pastrana D.V., Moskatel E., Sharma A.K. et al.: Mol. Cancer. Ther. 9, 2007 (2010).

33. Risberg K., Fodstad O., Andersson Y.: PLoS One 6, 1 (2011).

34. Du X., Xiang L., Mackall C., Pastan I.: Clin. Cancer. Res. 17, 5926 (2011).

35. Herrera L., Bostrom B., Gore L., Sandler E., Lew G. et al.: J. Pediatr. Hematol. Oncol. 31, 936 (2009).

36. Schindler J., Gajavelli S., Ravandi F., Shen Y., Parekh S. et al.: Br. J. Haematol. 154, 471 (2011).

37. Aruna G.: J. Stem. Cells. Regen. Med. 1, 31 (2006).

38. Pastan I., Hassan R., FitzGerald D.J., Kreitman R.J.: Annu. Rev. Med. 58, 221 (2007).

39. Dosio F., Brusa P., Cattel L.: Toxins 3, 848 (2011).

40. Kreitman R.J.: AAPS J. 8, 532 (2006).

41. Srivastava S., Luqman S.: Biomed. Res. Ther. 2, 169 (2015).

42. Madhumathi J., Verma R.S.: Curr. Opin. Microbiol. 15, 300 (2012).

43. Kreitman R.J., Wilson W.H., Bergeron K., Raggio M., Stetler-Stevenson M. et al.: N. Engl. J. Med. 345, 24 (2001).

44. Foss F.M., Bacha P., Osann K.E.: Clin. Lymphoma 1, 298 (2001).

45. Frankel A.E., Fleming D.R., Hall P.D., Powell B.L., Black J.H. et al.: Clin. Cancer. Res. 9, 3555 (2003).

46. Dang N.H., Hagemeister F.B., Pro B., McLaughlin P., Romaguera J.E. et al.: J. Clin. Oncol. 22, 4095 (2004).

47. Frankel A.E., Powell B.L., Hall P.D., Case L.D., Kreitman R.J.: Clin. Cancer. Res. 8, 1004 (2002).

48. Sandler E.S., Homan A., Mandelle L., Michael A., Donna A.W. et al.: J. Pediatr. Hematol. Oncol. 28, 210 (2006).

49. Lowenberg B., Beck J., Graux C., Putten W.V., Schouten H.C. et al.: Blood 115, 2586 (2010).

50. Aplenc R., Alonzo T.A., Gerbing R.B., Lange B.J., Hurwitz C.A. et al.: J. Clin. Oncol. 26, 2390 (2008).

51. Choudhary S., Mathew M., Verma R.S.: Drug. Discov. Today. 16, 495 (2011).

52. Kioi M., Husain S.R., Croteau D., Kunwar S., Puri R.K.: Technol. Cancer. Res. Treat. 5, 239 (2006). 
53. Pai L.H., Bookman M., Ozols R.F., Young R.C., Smith J.W. et al.: J. Clin. Oncol. 9, 2095 (1991).

54. Hassan R., Bullock S., Premkumaret A., Robert J.K., Hedy K. et al.: Clin. Cancer. Res. 13, 5144 (2007)

55. Messing E.M., Reznikoff C.A.: J. Cell. Biochem. Suppl. 50, 56 (1992).

56. Van R.J.A., Van V.A.J., Wijngaarden S., K.M.G., Bijlsma J.W.J. et al.: Arthrit. Rheum. 48, 1229 (2003).
57. Stepanov A.V., Belogurov A.A., Ponomarenko N.A., Stremovskiy O.A., Kozlov L.V. et al.: PLoS One 6, 20991(2011).

58. LeMaistre CF.: Clin. Lymphoma 1, 37 (2000).

59. Li Y.M., Hall W.A.: Toxins 2, 2645 (2010).

60. Fitzgerald D.J., Wayne A.S., Kreitman R.J., Pastan I.: Cancer. Res. 71, 6300 (2011).

61. Becker N., Benhar I.: Antibodies 1, 39 (2012).

62. Wayne A.S., Fitzgerald D.J., Kreitman R.J., Pastan I.: Blood 123, 2470 (2014).

63. Alewine C., Hassan R., Pastan I.: Oncologist 20, 176 (2015).

Received: 08.09. 2017 